\title{
MITOS DALAM NOVEL MANUSIA LANGIT KARYA J.A. SONJAYA
}

\author{
Wahyu Mulayani
}

UNIROW Tuban, wahyumulyani60@gmail.com

\begin{abstract}
ABSTRAK
Mitos sebenarnya merupakan cerita masa lalu dari leluhur yang dianggap memiliki pesan dan makna kebenaran. Untuk itu sebagian masyarakat Indonesia khususnya masyarakat Nias tidak mau melanggar adat istiadat (yang sebenarnya mitos), karena takut kena tulah atao azab. Sonjaya banyak menceritakan tentang mitos yang ada di pulau Nias melalui novelnya yang berjudul Manusia Langit. Mitos yang diceritakan dalam novel Manusia Langit berkaitan dengan kehidupan sehari-hari di Nias. Selain itu, bahasa yang digunakan oleh Sonjaya indah, sehingga cocok untuk dikaji. Tujuan penulisan ini untuk mendeskripsikan 1) bentuk mitos percintaan dalam novel Manusia Langit karya Sonjaya, 2) bentuk mitos religius dalam novel Manusia Langit karya Sonjaya. Penulisan ini menggunakan pendekatan antropologi sastra, karena yang dibahas tentang mitos yang merupakan salah satu unsur budaya. Budaya merupakan cultural bangsa sehingga masing-masing memiliki kepercayaan yang berbeda. Metode yang digunakan adalah deskriptif kualitatif. Manfaat yang diharapkan dalam penulisan ini, 1) dapat menambah jumlah penelitian sastra khususnya tentang mitos. 2) dapat menghibur, menambah pengetahuan dan memperkaya wawasan pembacanya dengan cara yang unik, yaitu melalui bentuk naratif. Sehingga pesan yang disampaikan kepada pembaca tidak terkesan menggurui. Hasil dari pembahasan 1) mitos percintaan, menceritakan hubungan antara tokoh Mahendra dengan kekasihnya, 2) mitos religius menceritakan para leluhur Nias yang menganut kepercayaan animisme. Masyarakat Nias masih mendewakan roh-roh yang tidak kelihatan (roh halus) dan memuja roh-roh yang berbentuk, seperti patung yang di buat dari bahan batu atau kayu, serta pohon tertentu yang dianggap memiliki kekuatan gaib.
\end{abstract}

Kata kunci: Mitos percintaan, Mitos religius, Novel Manusia Langit 


\section{PENDAHULUAN}

Di Era Globalisasi ini masih ada masyarakat Indonesia yang percaya pada mitos. Mitos sebenarnya merupakan cerita masa lalu dari leluhur yang dianggap memiliki pesan dan makna kebenaran. Menurut Levi-Strauss (dalam Endraswara, 2003:110)mitos tidak lebih sebagai dogeng. Dogeng merupakan sebuah kisah atau cerita yang lahir dari hasil imajnasi manusia, dari khayalan manusia, dalam kehidupan sehari-hari. Melalui dogeng tersebut khayalan manusia memperoleh kebebasan mutlak, karena manusia bebas menciptakan apa saja. Hal-hal yang tidak masuk akal pun boleh terjadi dalam dogeng. Misalnya dogeng Kancil dan Gajahyang menokohkan seekor kancil yang mampu memperdaya gajah.

Mitos tidak selalu relevan dengan sejarah dan kenyataan. Mitos juga tidak selalu bersifat sakral atau wingit(suci). Oleh karena itu, mitos yang suci pada suatu tempat, ditempat yang lain dianggap biasa. Mitos yang oleh sekelompok manusia diyakini kenyataan, di tempat yang lain dianggap khayalan saja. Misalnya ada burung prenjak bertengger di pohon sekitar rumah sambil berbunyi. Ada sebagian kelompok manusia yang menyakini rumah tersebut akan ada tamu, dan kelompok manusia yang lain menganggap hal yang biasa saja.

Mitos merupakan pengungkapan fenomena kultural yang menarik dari setiap daerah. Setiap daerah memiliki mitos sendiri-sendiri sesuai kultur atau budaya yang dianutnya. Sonjaya menggambarkan kultur budaya masyarakat Nias yang masih percaya dengan mitos melalui karyanya yang berjudulManusia Langit. Novel Manusia Langit merupakan hasil penelitian Sonjaya di Nias dan Yogyakarta yang dikemas dalam bentuk novel yang menarik, dengan tujuan pembaca memahami tentang mitos yang masih di percaya oleh sebagian masyarakat Indonesia khusunya Nias. 
Novel Manusia Langit merupakan media yang digunakan oleh Sonjaya untuk menyampaikan gagasan-gagasan, pemikiran-pemikiran, dan pengalamannya selama di pulau Nias. Selain itu, Sonjaya menyampaikan realitas sosialyang pernah terjadi di masyarakat Indonesia khusus di Nias dihadirkan kembali dalam bentuk dan cara yang berbeda.

Sonjaya sebagai penulis Novel Manusia Langit meninjau mitos dari aspek sinkronik dan diakronik, karena novel Manusia Langit di tulis selama lima tahun yaitu mulai tahun 2005 sampai 2010. Menurut Levi Strauss (dalam Endraswara 2002 :112) mitos dapat dilihat dari dua aspek yaitu aspek sinkronik dan diakronik. Aspek sinkronik adalah mitos yang diyakini sebagai peristiwa masa lampau namun masih relevan untuk masa kini. Aspek diakronik adalah mitos yang yang berasal dari masa lalu tetapi tetap ada sampai sekarang.

Tujuan penulisan ini untuk mendeskripsikan 1) bentuk mitos percintaan dalam novel Manusia Langit karya Sonjaya, 2) bentuk mitos religius dalam novel Manusia Langit karya Sonjaya. Penulisan ini menggunakan pendekatan antropologi sastra, karena yang dibahas tentang mitos yang merupakan salah satu unsur budaya. Budaya merupakan cultural bangsa yang masing-masing memiliki kepercayaan berbeda. Penulisan ini merupakan penelitian pustaka untuk itu , metode yang digunakan adalah deskriptif kualitatif. Manfaat yang diharapkan dalam penulisan ini, 1) dapat menambah jumlah penelitian sastra khususnya tentang mitos, 2) dapat menghibur, menambah pengetahuan dan memperkarya wawasan pembacanya dengan cara yang unik, yaitu melalui bentuk naratif. Sehingga pesan yang disampaikan kepada pembaca tanpa terkesan menggurui. 


\section{HASIL DAN PEMBAHASAN}

\section{Bentuk Mitos Percintaan Dalam Novel Manusia Langit Karya Sonjaya}

Sonjaya dalam Novel Manusia Langitmenceritakan tentang kehidupan seorang dosen Arkeologi yang masih muda bernama Mahendra. Mahendra digambarkan sebagai dosen muda di sebuah Perguruan Tinggi di Yogyakarta, yang berusaha melepaskan diri dari duniakampus, dan peraturan yang membelenggunya.

Sebagai seorang dosen muda Mahendra tertarik dengan mahasiswanya yang bernama Yasmin. Namun hubungan cinta kasih di kampus itu tidak bisa berlanjut karena adat dan budaya yang berbeda. Kemudian dia pergi meninggalkan dunia kampus dan mencari bumi baru untuk menghilangkan kegundahan hati menuju Nias.

Kehidupan di Yogyakarta dengan di Nias menurut Mahendra jauh berbeda. Setelah beberapa tahun lamanya Mahendra meninggalkan dunianya beserta para manusia langit (kampus dan kota yogyakarta) perlahan-lahan Mahendra mulai kerasan dengan bumi dan para manusia langit yang baru. Di bumi Nias Mahendra bertemu dengan seorang gadis yang bernama Saita, kemudian memiliki hubungan cinta kasih, tetapi gagal juga karena adat. Mahendra putus asa mau pulang ke Yogyakarta, namun dilarang oleh Ama Budi yang baik hati serta dapat saling memahami kekurangan.Ama Budi begitu Mahendra memanggil pemilik rumah dan tetua adat masyarakat Nias, hingga dapat dianggapnya anak dan keluarga sendiri oleh keluarga Ama Budi.Begitu pula dengan putra Ama Budi yang bernama Sayani yang begitu senantiasa membela dan membantu Mahendra dalam segala hal, bahkan Sayani juga ikut menggali tanah di Nias.

44 | http://journal.unesa.ac.id/index.php/paramasastra 
Wahyu Mulayani, Mitos dalam Novel... (hlm. 41-55)

Ketika Sayani dan Mahendra sedang duduk santai tiba-tiba ada burung elang yang beterbangan di atas langit. Sayani menceritakan tentang burung elang yang terbang di atasnya kepada Mahendra. Hal ini tersurat pada kutipan

Bang!” Sayani membuyarkan lamunanku. "sejak kapan moyo itu terbang di atas kita?" tanya Sayani sambil menunjuk seekor burung elang yang sedang terbang di atas kita.

“tidak tahu, memang kenapa?” “ah, bukan apa-apa, Bang...”

"tapi kamu tampak cemas, ada apa dengan burung itu?"

"jika ia terbang berputar dan tampak bingung, itu artinya aka ada petaka bagi kita yang ada di bawahnya."

“tapi elang itu tidak seperti bingung."

"lihat kepalanya, Bang ia tidak fokus kebawah mencari mangsa, tapi lebih sering mendongak kelangit."

"petaka seperti apa?”

“kematian.”.(ML, hal 8)

Orang modern seperti Mahendra tidak percaya akan cerita itu, karena dia orang modern yang mengajar di sebuah perguruan tinggi di Yogyakarta. Tetapi ia lupa bahwa lain daerah lain tata cara dan adat kepercayaannya. Mahendra 
menganggap cerita itu mitos dan sebuah cerita klasik yang tidak bermakna. Namun kenyataannya mitos itu benar-benar membawa petaka dan musibah bagi Sayani. Karena Sayani meninggal dengan cara membakar dirinya, untuk menjaga nama baik Mahendra.

Hal ini tersurat Pada kutipan di bawah ini.

" nenek ini telah menceritaknya semuanya kepadaku, setelah memukulmu, Sayani segera mengganti pakaiannya dengan pakaianmu ia lalu membakar diri bersama Saita di dalam gubuk itu agar semua masalah terkait nak Hendra dan Saita selesai. Biar semua orang tahu bahwa kalian berdua sudah tiada."(ML, hal 185).

Kerpercayaan terhadap burung elang itu, sebenarnya tidak hanya masyarakat Nias, tetapi juga di beberapa daerah di Indonesia, seperti di Jawa, Madura masih menyakini jika burung elang adalah burung pembawa kabar petaka atau burung pembawa kabar kematian bagi orang yang berada di sekitarnya. Dan sebagian ada yang beranggapan mitos yang mengarah ke syirik. Bila elang yang terbang bimbing bearti petaka, tetapi bila elang terbang lincah menggambarkan jiwa pemuda.Hal ini tersurat pada kutipan di bawah ini.

"elang yang terbang bimbang berarti petakan, tapi elang yang terbang lincah menggambarkan jiwa pemuda. "(ML, hal 174)

Mitos di Nias tidak saja terjadi pada burung elang, tetapi juga terjadi pada burung prenjak, gagak hitam, perkutut, hanya saja dalam Manusia Langit tidak tertulis secara lengkap. Cerita lain seperti Sirao dikatakan anak dari hasil perkawinan dua angin di langit, dan proses perkawinannya seperti perkawinan 
Wahyu Mulayani, Mitos dalam Novel... (hlm. 41-55)

manusia. Hal ini diceritakan oleh tokoh Ama Budi kepada tokoh Mahendra. Seperti yang tersurat pada kutipan di bawah ini.

Sirao adalah anak dari hasil perkawinan dua angin dilangit. Proses perkawinan adalah kehamilan angin tersebut di ceritakan secara jelas layaknya perkawinan dan kehamilan manusia (ML, 110).

Berdasarkan kutipan tersebut maka suku Nias dianggapa berasal dari langit. Namun dari versi cerita yang lain suku Nias dianggap berasal dari sebuah pohon kehidupan yang disebut Sigaru Tora'a.

Kutipan-kutipan di atas secara rasio tidak masuk akal untuk itu disebut mitos. Mitos menurut Barthes (dalam Rafiek, 2012:103-105) dapat hidup dalam suasana tindakan revolusioner dengan cara berkhayal. Mitos apapun dengan derajat generalisasi tertentu pada dasarnya bersifat ambigu, karena dia mewakili kemanusiaan. Mitos juga merupakan sistem komunikasi karena mitos merupakn sebuah pesan. Mitos dapat tumbuh dan berkembang dalam karya sastra sesuai dengan kreativitas pengarangnya.

\section{Bentuk Mitos Religius Dalam Novel Manusia Langit Karya Sonjaya}

Novel Manusia Langit selain menggambarkan tentang kultur atau budaya pada umumnya juga menggambarkan kereligiusan masyarakat Nias yang berbeda dengan masyarakat lain. Religius adalah suatu cara pandang seseorang mengenai agamanya serta bagaimana orang tersebut menggunakan keyakinannya atau agamanya dalam kehidupan sehari-hari (Earnshaw:2000).

http://journal.unesa.ac.id/index.php/paramasastra | 47 
Di Nias masyarakatnya masih menganut ajaran atau aliran animisme. Animisme adalah kepercayaan kepada makhuk halus dan roh yang merupakan azas kepercayaan agama yang mula-mula muncul dikalangan manusia primitif. Ajaran animisme mempercayai setiap benda di Bumi (seperti kawasan tertentu, gua, pohon atau batu besar) yang mempunyai jiwa dan harus dihormati agar tidak mengganggu manusia, bahkan dapat membantu untuk mengusir roh jahat dalam kehidupan sehari-hari (https://id.m.wikipedia.org ).

Di Nias digambarkan masyarakatnya masih percaya dengan hal-hal gaib. Seperti yang tersurat pada kutipan di bawah ini.

sudah pulang rupanya kalian?" sapa Ama Budi. "lekas mandi keburu malam, nanti kena tesafo di sungai!"

“baik Ama!"aku sangat merinding mendengar kata tesafo. Aku pernah melihat tetangga Ama Budi yang kesurupan roh halusbeberapa hari yang lalu. Mengerikan sekali. (ML, hal 14).

Tesafo merupakan penyakit yang ditimbulkan oleh makhluk halus, menurut kepercayaan masyarakat Nias. Biasanya seseorang yang terkena tesafo akan segera di beri tanda salip pada dahinya dengan menggunakan bahan dapur yaitu kunyit atau arang.

Menurut masyarakat Nias tesafoadalah makhluk halus yang belum tenang jiwanya. Maksudnya bila ada orang yang meninggal belum diadakan ritual maka jiwanya akan tidak tenang. Satu ritual khusus setelah kematian di Nias adalah doa setelah empat hari dari kematian. Arwah orang yang meninggal diundang dan di beri makan untuk terakhir kalinya. Ada kepercayaan bahwa selama empat hari setelah meniggal arwah masih di dalam atau di sekitar rumah. Di saat hari upacara atau ritual kematian, tidak ada seorang pun yang di perbolehkan berada di tenggah jalan, apalagi berada di pintu rumah karena bisa terkena tesafo. Arwah akan 48 | http://journal.unesa.ac.id/index.php/paramasastra 
Wahyu Mulayani, Mitos dalam Novel... (hlm. 41-55)

dijamu secara khusus dengan menyembelih babi dan setelah empat hari, diyakini bahwa arwah itu sudah siap meninggalkan segala sesuatu yang ada di dunia dan pulang kepada Lowalani. Dan jika seseorang yang terkena tesafo tidak segera di tolong, atau terlambat maka akan berakhir dengan kematian. Selain tesafo masyarakat Nias juga percaya pada roh leluhur yang masih dianggap hidup dan bisa memberi perlindungan pada keturunannya. Hal ini tersurat pada kutipan di bawah.

Bapak ini bilang, soal izin nanti akan mereka bicarakan lagi dengan Pak Mböwö Laiya. Tapi, katanya jika Bang Mahendra ingin tahu sejarah Banuaha, datang saja kerumahnya. Pak Nai Laiya bisa mengundang roh leluhur datang kerumahnya. Bang Mahendra bisa bicara dengan roh itu, termasuk bertanya tentang sejarah Banuaha. Tidak usah repot-repot menggali katanya”(ML, hal 5).

Kutipan di atas jelas menunjukan bahwa masyarakat Nias masih percaya pada halhal yang gaib. Sikap dan perilaku masyarakat Nias masih taat atau patuh dalam menjalankan ajaran agama yang dipeluknya (animisme). Masyarakat Nias masih memuja dan meminta sesuatu lewat adu zatua atau patung orang tua. Patung ini dianggap bisa berkomunikasi layaknya manusia.

Kata Pak Nai Laiya, Bang Mahendra bisa bicara pada leluhur melalui adu zatua, patung orang tua, di rumah pak Nai Laiya (ML, hal 6). 
Selain itu Masyarakat Nias juga percaya pada Lowalani,yang dianggap sebagai penguasa bumi dan langit untuk keselamatan. Hal ini tersurat pada kutipan di bawah.

Pada saat yang menegangkan itu, nenek ingat untuk berdoa pada Lowalani, penguasa bumi dan langit, agar aku yang baru saja di lahir dilancarkan jalan napasnya. Lowalani ternyata menjawab permohonan nenek dalam bentuk petir yang sambar menyambar dilangit. Tidak lama berselang, aku pun bisa mengeluarkan tangisan pertama. Suaraku membehana di sekitar ladang seperti bunyi kentungan yang memangil para tetangga di gubuk-gubuk yang berdekatan. Beberapa perempuan dewasa dan gadis datang menghampiri gubuk kamiyang beralaskan tanah itu (ML, hal 18).

Lowalani dianggap leluhur yang paling menakutkan dan menyebut namanya pun harus hati-hati tidak bisa sembarangan, kalau sembarangan akan kena azab yang dahsat. Hal ini tersurat pada kutipan di bawah.

"tadi aku menyebut leluhurku, Lowalani, tidak boleh itu, tidak boleh sembarangan menyebut namanya. Harusnya aku membaca doa dan memotong ayam dulu sebelum menyebutnamanya. Dia yang di langit sana bisa marah, "ujar Ama Budi. Angin berembus kencang di dalam ruangan kala Ama Budi menyebut kembali nama Lowalani. Sayani mengusap kuduknya sambil melirik kanan-kiri. Ia tampak ketakutan. "tidak apa-apa,"kata Ama Budi berusaha menenangkan anaknya. “dia sudah pergi” (ML, hal 19).

Apa yang dilakukan oleh Ama Budi menyebut nama Lowalani, tidak sengaja, karena asyik bercerita kepada Mahendra dan Sayani. NamunLowalani 50 | http://journal.unesa.ac.id/index.php/paramasastra 
Wahyu Mulayani, Mitos dalam Novel... (hlm. 41-55)

marah, sehingga yang kena sasaran kutukan adalah Ibu Sayani. Ibu Sayani meninggal dunia karena kesalahan Ama Budi yang tidak sengaja menyebut Lowalani tanpa doa dan sesaji lebih dulu. Kematian Ibu Sayani diceritakan pada kutipan di bawah.

Aku melihat Ama Budi tengah termenung. Ia sama sekali tak menangis menghadapi istrinya terbujur kaku. Sayani dan Ina Berna yang menangis paling keras.aku memeluk Ama Budi erat, merasa sangat menyesal dan takut. Lagi-lagi, ini gara-gara aku yang memancing Ama Budi menyebut nama leluhur tanpa syarat adat. Ama Budi pasti berpikit seperti itu (ML, hal113).

Menurut mitologi Nias, alam serta seluruh isinya adalah ciptaan Lowalangi. Langit yang diciptakannya berlapis sembilan. Setelah selesai menciptakan semua itu, beliau kemudian menciptakan satu pohon kehidupan yang disebut Tora'a. Pohon itu kemudian berbuah dua buah, yang setelah dierami seekor laba-laba emas, yang juga merupakan ciptaan Lowalangi, menetaslah sepasang dewa pertama di alam semesta ini. Mereka ini bernama Tuhamora'aangi Tuhamoraana'a yang berjenis laki-laki dan Burutiraoangi Burutiraoana'a yang berjenis perempuan. Keturunan sepasang dewa pertama ini kemudian mendiami sembilan lapis langit. Untuk menciptakan sesuatu itu, Lowalani mempergunakan udara dari berbagai warna sebagai bahannya. Warna-warna itu ia aduk dengan tongkat gaib yang disebut sihai.

Sonjaya menggambarkan kehidupan masyarakat Nias yang masih menganut aliran animisme dengan gamblang. Status sosial dalam kehidupan masyarakat Nias sangat religius sesuai agama yang dianutnya. Setiap ada orang tua yang meninggal dibuat patung untuk di pajang di rumahnya. Dianggap arwah 
orang tuanya masih tinggal di dalam patung tersebut. Sehingga kalau anakanaknya mempunyai inginan atau hajat tinggal meminta pertolongan pada patung orang tuanyaagar hajat terkabul, namun dengan membawa sesaji.

Bentuk penghormatan terhadap leluhur itu diwujudkan dalam simbol patung yang di sebut Adu Zatua patung ini diletakkan didalam rumah pada kisikisi tembok ataupun pada bagian di sekitar tiang penyangga utama. Penghormatan terhadap leluhur tersebut juga ditemukan pada keseharian masyarakat Nias yang masih menyebut kata leluhur jika mendapat musibah atau mendapatkan keberuntungan. Penyebutan leluhur tersebut mengidikasikan bahwa leluhur yang dianggap berada di alam lain masih memiliki hubungan yang erat dengan keturunannya di alam nyata. Ungkapan dalam bentuk terimakasih jelas menunjukkan bahwa leluhur dianggap dapat memengaruhi kehidupan keturunannya. Untuk menjaga agar kepercayaan terhadap leluhur tetap dalam sistem, maka struktur masyarakat dalam sebuat satuan keluarga sangatlah penting dalam kaitanya dengan kepercayaan terhadap leluhur. Sebagai contoh adalah silsilah dalam hoho turunya leluhur masyarakat Nias jelas disebutkanadanya silsilah awal masyarakat Nias kemudian menghasilkan keturunan hingga sekarang. Namun harus hati-hati dengan roh jahat pemakan bayi. Hal ini tersurat pada kutipan di bawah.

....karena sering hilang dimakan roh halus itulah, populasi belada akhirnya tidak banyak dan tidak berkembang, bahkan punah. Anak-anak bayi mereka seringhilang di makan roh jahat. Cerita itumasih hidup hingga sekarang. Banyak orang kita sekarang yang masih memercayai roh pemakan bayi itu."(ML, hal 20).

52 | http://journal.unesa.ac.id/index.php/paramasastra 
Kepercayaan akan adanya alam lain (alam yang tidak tampak), sangat diyakini oleh masyarakat Nias. Roh yang hidup di alam lain dapat mengaruhi kehidupan orang yang masih hidup. Adanya lapisan langit yang berstruktur erat kaitanya dengan ritual yang dijalankan dalam upaya pencapaian tingkat sosial tertentu.

Selain Adu Zatwa, Lowalani, juga ada pohon tertentu yang anggap keramat dan memiliki kekuatan gaib untuk sesembahan, bila ingin sesuatu, tetapi harus memberi sesaji lebih dulu pada pohon tersebut, agar sesuatu tersebut bisa berhasil.

Dalam novel Manusia Langit menggambarkan relegius masyarakat Nias melalui sikap dan perilaku yang masih percaya dengan hal-hal gaib, dan roh-roh halus dari leluhur, patung orang tua yang bisa membantu dan menolong bila memiliki keinginan atau hajat. Hal ini bila dipandang dari sudut agama Islam cenderung syirik.Namun bila dipandang dari sudut pandang seni sastra sangat menarik.

\section{SIMPULAN}

Mitos di Indonesia dapat tumbuh dan berkembang dalam karya sastra sesuai kreativitas pengarangnya. Mitos yang di narasikan oleh Sonjaya dalam novelnya yang berjudul Manusia Langit dapat disimpulkan secara singkat di bawah.

Mitos percintaan, menceritakan hubungan antara tokoh Mahendra dengan kekasihnya, yang selalu terhalang oleh adat dan budaya.Mitos ini ditandai dengan datangnya burung elang yang terbang bimbang berarti petakan. Hal ini terbukti 
karena kekasih Mahendra yang bernama Saita meninggal dunia dengan caramenggantung diri dan Sayani Membakar diri. Selain itu juga menceritakan tentang Sirao adalah anak dari hasil perkawinan dua angin dilangit

Mitos religius menceritakan dewa-dewa. Para leluhur Nias masih menganut kepercayaan animisne yang diikuti oleh anak cucunya. Selain itu masyarakat Nias juga mendewakan roh-roh yang tidak kelihatan yaitu roh leluhur.Memuja roh-roh yang berbentuk, sepertipatung yang di buat dari bahan batu atau kayu yaitu patung orang tua yang sudah meninggal. Pohon tertentu yang dianggap keramat dan memiliki kekuatan gaib

\section{DAFTAR PUSTAKA}

Aminuddin, 2013. Pengantar Apresiasi Karya Sastra. Bandung: Sinar Baru Algensindo Bandung

Aziez, Furqonul (dkk). 2010. Menganalisis Fiksi, Sebuah Pengantar. Bogor: Ghalia Indonesia

Endraswara, Suwardi, 2013. Metodologi Penelitian Sastra. Yogyakarta: caps (center for academic publishing service)

Endraswara, Suwardi, 2013. Teori Kritik Sastra. Yogyakarta: Caps (Center For Academic Publishing Service)

Endraswara, Suwardi. 2013. Metodologi Penelitian Antroologi Sastra. Yogyakarta: Penerbit Ombak

Faruk. 2012. Pengantar sosiologi sastra. Yogyakarta: Pustaka Pelajar Offset.

Nurgiyantoro,Burhan.2010.Teori Pengkajian Fiksi. Yogyakarta: Gadjah Mada University Press.

54 | http://journal.unesa.ac.id/index.php/paramasastra 
Wahyu Mulayani, Mitos dalam Novel... (hlm. 41-55)

Purwadi, 2009. Pengkajian Sastra Jawa. Yogyakarta: Pura Pustaka Yogyakarta

Ratna, Nyoman Kutha, 2015. Teori, Metode, Dan Teknik Penelitian Sastra. Yogyakarta: Pustaka Belajar.

Satoto, Soediro, 2012. Metode Penelitian Sastra. Surakarta: Yuma presindo.

Slamet, Riyadi. 1994.Idiom Tentang Nilai Budaya Sastra Jawa. Jakarta: Departemen Pendidikan Dan Kebudayaan.

Sonjaya, J.A. 2010. Manusia Langit. Yogyakarta : Kompas.https://id.m.wikipedia.org>wiki> 